\title{
"NO EXTINGÁIS EL ESPÍRITU" (1TES 5,19): LA IGLESIA, LOS CARISMAS Y EL PRIMADO DE LA CARIDAD A PARTIR DEL DOCUMENTO VI DEL DIÁLOGO CATÓLICO-PENTECOSTAL
}

"Do not quench the Spirit" (1Thess 5,19): The Church, The Charisms, and the Primacy of Love from Document VI of the Catholic-Pentecostal Dialogue

Marcial Maçaneiro *

RESUMEN: El artículo aborda el tema de los carismas y el primado de la caridad en la Iglesia, a partir del Documento VI del Diálogo Internacional Católico-Pentecostal. Es un análisis inicial del documento, publicado al final de la Sexta Etapa de este Diálogo, bajo el título Los carismas en la vida y en la misión de la Iglesia (2016). El tema elegido corresponde a la Parte II del documento, que reflexiona sobre la diversidad de los carismas, el primado de la caridad, la relación entre carismas y servicio. El análisis articula Pneumatología y Eclesiología, con tres tópicos: 1) la Iglesia, los carismas y la caridad; 2) manifestación de los carismas; 3) la Iglesia en permanente Pentecostés. Al final, son señalados dos aspectos: la relación entre los sacramentos y el Espírito, y las condiciones de recepción del mismo Documento VI por parte de las iglesias.

PALABRAS-CLAVE: Diálogo católico-pentecostal. Espíritu Santo. Iglesia. Carismas.

ABSTRACT: This article addresses the issue of charisms and the primacy of charity in the Church, based on Document VI of the International Catholic-Pentecostal Dialogue. It is an initial approach to the document, published at the end of the Sixth Phase of this Dialogue, under the title Charisms in the life and mission of the Church (2016). In this article, the chosen theme is concentrated in Part II: a reflection on diversity of charisms, primacy of love, and the relationship between charisms

* Pontifícia Universidade Católica do Paraná, Curitiba, Paraná, Brasil. 
and service. The analysis articulates Pneumatology and Ecclesiology, with three topics: 1) the Church, the charisms and love; 2) charisms manifestation; 3) the Church in permanent Pentecost. At the conclusions, two aspects are pointed out: the relationship between the sacraments and the Spirit, and the conditions for a reception of the Document VI by the Churches.

KEYWORDS: Catholic-Pentecostal Dialogue. Holy Spirit. Church. Charisms.

\section{Introducción}

$\mathrm{D}$ e 2010 a 2015, representantes de la Iglesia Católica y de las Iglesias Pentecostales clásicas cumplieron la Sexta Etapa del Diálogo Internacional Católico-Pentecostal, que resultó en la publicación del respectivo Documento VI: "No extingáis el Espíritu" $(1$ Tes 5,19) - Los carismas en la vida y en la misión de la Iglesia INTERNATIONAL COMMISSION FOR CATHOLIC-PENTECOSTAL DIALOGUE, (ICCaPD), (2016, edición en línea). Fue la más reciente de las etapas de este Diálogo, desde 1972; cada cual con su tema y Documento Final (ediciones indicadas entre paréntesis):

1a etapa: el bautismo en el Espíritu Santo y la iniciación cristiana; relación entre Escritura y Tradición; persona, dones y carismas: 1972-1976 COMMISSIONE INTERNAZIONALE DI DIALOGO CATTOLICO-PENTECOSTALE (CIDCaP), 1994.

2- etapa: la fe, la experiencia religiosa y el hablar en lenguas; el rol de María: 1977-1982 (CIDCaP, 1995).

3 a etapa: perspectivas sobre koinonia y comunión cristiana: 1985-1989 (CIDCaP, 1995).

4⿳亠丷厂 etapa: evangelización, proselitismo y testimonio común: 1991-1997 (PCUC, 1999).

5 5 $^{\text {a }}$ etapa: hacerse cristiano: conversión, iniciación cristiana, bautismo en el Espíritu Santo y discipulado, con base bíblica y patrística: 1998-2006 (CIDCaP, 2010).

6 6 $^{\text {a }}$ etapa: carismas en la vida y misión de la Iglesia: 2011-2015; con tres carismas subrayados: profecía, sanación y discernimiento de los espíritus (CIDCaP, 2018).

La 7a etapa fue abierta en 2018 en los Estados Unidos, sobre Lex orandi, Lex credendi: la relación entre fe, vida y medios de gracia; con actividades en progreso, se la espera concluir en 2022.

Como mencionado, los participantes representan al pentecostalismo clásico, cuyas iglesias son herederas de las primeras generaciones del Movi- 
miento Pentecostal moderno, desarrolladas posteriormente como cuerpos misioneros y ministeriales propios, con estructura eclesiástica y teología estables. Suman 22 instituciones, entre Iglesias y federaciones pentecostales, asociadas en gran parte a la World Pentecostal Fellowship (Conferencia Mundial Pentecostal). Participan: Asambleas de Dios, Iglesia Pentecostal de Santidad, Iglesia de Dios, Iglesia del Evangelio Cuadrangular, Misión de Fe Apostólica, Iglesia del Pentecostés, Iglesia Biblia Abierta, Iglesia del Dios de la Profecía, con las Asambleas Pentecostales de Canadá, Unión de Iglesias Pentecostales y Carismáticas (EUA) y Consejo de Iglesias Pentecostales de Gana (África), entre otras. En la metodología de este Diálogo, las iglesias y federaciones pentecostales participan en grupo, representadas por aproximadamente 8 expertos, designados y reconocidos por las respectivas jerarquías. Del lado católico, los expertos, en igual número, son designados por el Pontificio Consejo para Promoción de la Unidad de los Cristianos (Vaticano) - entre los cuales, el autor de estas páginas. De esta manera, a pesar de la cantidad de iglesias pentecostales, los estudios y conversaciones se desarrollan como diálogo bilateral.

El reciente Documento VI sobre los carismas en la Iglesia resulta de cinco coloquios anuales, de 2011 a 2015, que constituyeron la Sexta Etapa de este Diálogo Internacional. El texto está dispuesto en los siguientes apartados:

\section{I - Introducción (n. 1-8)}

II - Carismas en la vida y misión de la Iglesia (n. 9-28)

III - Reflexión sobre carismas específicos (n. 29-90)

IV - Supervisión pastoral del ejercicio de los carismas (n. 91-104)

V - Síntesis final y conclusiones (n. 105-114)

La Introducción hace un recorrido de los participantes, el escopo y el método de la Sexta Etapa del Diálogo Católico-Pentecostal. A continuación, los Carismas en la vida y la misión de la Iglesia (Parte II) presenta el fundamento bíblico y teológico de los dones carismáticos, bajo el signo de una eclesiología trinitaria: la Iglesia referida al Padre como Pueblo de Dios; al Hijo, como Cuerpo de Cristo, y al Paráclito, como Templo del Espíritu con sus inevitables reciprocidades. Por cierto, la cuestión de los carismas favorece un enfoque pneumatológico en la eclesiología ${ }^{1}$; pero sin dejar de articular éstas tres realizaciones de la una Iglesia de Cristo, que tiene en la Trinidad su arché primordial (LG, n. 2-4)2. En esta Parte II se verifica también el testimonio patrístico y los principales pasos de las manifestaciones

\footnotetext{
${ }^{1}$ Si bien el español suele escribir Neumatología, preferimos Pneumatología para explicitar la radical griega "pneuma" (espíritu).

${ }^{2}$ Los documentos del magisterio católico se citan con las siguientes siglas: AA - Apostolicam Actuositatem, EG - Evangelii Gaudium, JE - Juvenescit Ecclesia, LG - Lumen Gentium.
} 
carismáticas en la Iglesia reciente. Tal enfoque histórico-teológico permitió a católicos y pentecostales tres aproximaciones: a la Historia de las Iglesias, considerando la experiencia carismática de Movimientos y Comunidades más allá del pentecostalismo; a la eclesiología de comunión, donde los carismas tienen su lugar para la edificación y renovación del Cuerpo de Cristo; al testimonio bíblico de los carismas como dones para servir, bajo el amor, no reducibles a las expresiones miraculosas o extraordinarias.

La Reflexión sobre carismas específicos (Parte III) es la más extensa, dedicada a tres dones: profecía (n. 30-51), cura (n. 52-72) y discernimiento de los espíritus (n. 73-90). Fue una elección motivada por la relevancia de estos dones para la vida eclesial. Aunque todos los carismas son importantes, la Comisión subraya la profecía y la sanación por dos razones: positivamente, por las gracias que estos carismas reservan a la Iglesia como manifestación de la verdad evangélica (profecía) y como experiencia de salvación (cura), conforme a las Escrituras; y negativamente, por las situaciones problemáticas que el ejercicio de estos dones conlleva, muchas veces, en la vida de las comunidades. Eso pide de la Iglesia un cuidado permanente, por medio de la supervisión pastoral y el discernimiento de los espíritus. De este modo se presentan, en secuencia, los tres carismas destacados en la Parte III del Documento. La profecía es comprendida sea como carácter de todo el Pueblo de Dios según el triple munus profético-real-sacerdotal, sea como carisma ejercido en la libertad del Espíritu. En este sentido, la profecía ocurre no solo como exhortación y proclamación de la Palabra, sino también como promoción de la justicia y de la paz, en testimonio de los valores del Reino de Dios, muchas veces en medio a las persecuciones (n. 44 y 51). La sanación, por su vez, es comprendida como experiencia de liberación del mal y salvación integral de la persona humana (no solo en nivel físico), en advertencia contra las falsas curas, la espectacularización del culto y la vanagloria de ministros que buscan autopromoción (n. 67, 70 y 72).

La Supervisión Pastoral (Parte IV), a su vez, ofrece criterios de discernimiento, valoración y práctica de los carismas, acercando teología y pastoral, criterios doctrinales e indicaciones prácticas. En el apartado Síntesis y conclusiones (Parte V), católicos y pentecostales manifiestan su reflexión final, a la vez evaluativa y prospectiva: reafirman juntos la vitalidad carismática de la Iglesia, llamada a realizarse como comunión; evalúan el propio Diálogo como una peculiar experiencia del Espíritu Santo, que actúa en beneficio de la unidad del Cuerpo de Cristo; y recomiendan la divulgación y el estudio del Documento VI a las Iglesias (a partir de cuántas lo han firmado), con atención a los sujetos y procesos de formación, especialmente quienes se dedican a la enseñanza, la educación teológica y capacitación pastoral.

En las presentes páginas tratamos sobre la vitalidad carismática y el primado de la caridad en la Iglesia, a partir de la Parte II. Es un primero 
análisis del Documento VI, a cuya lectura integral invitamos a todos y todas. Nuestra exposición tiene tres partes: 1) la Iglesia, los carismas y la caridad; 2) manifestación de los carismas; 3) la Iglesia en permanente Pentecostés. De este modo releemos el Documento VI, con su base bíblica y magisterial acompañada de reflexión teológica, en la articulación entre Pneumatología y Eclesiología, con atención a los criterios de la caridad y del servicio en la valoración de los carismas. Al final, señalamos dos aspectos que requieren atención: la relación entre los sacramentos y el Espírito y las condiciones de recepción del mismo Documento por parte de las Iglesias y Comunidades locales.

\section{La Iglesia, los carismas y la caridad}

A partir de las Escrituras, católicos y pentecostales admiten la "naturaleza carismática de toda la Iglesia" (Documento VI, n. 9). Sin embargo, hay que esclarecer que al decir "naturaleza" no se afirma solamente la manifestación de los carismas, sino la constitución pneumatológica de la Iglesia en su "naturaleza" de matriz trinitaria: nacida del amor del Padre, fundada en Jesucristo el Mesías, vivificada per el Espíritu Santo (LG, n. 2-4)3.

En otros términos: el Espíritu Santo constituye y realiza la Iglesia en Cristo, puesto que es el Espíritu de Verdad, Paráclito, Vivificador, Artífice de la comunión y de la misión, Don de Dios por excelencia. Así como el Espíritu habitó el Cuerpo encarnado del Mesías, análogamente el mismo Espíritu habita la Iglesia y la vivifica, como observa Mühlen, de manera que en la Iglesia se extiende por los siglos la plenitud del Espíritu de Cristo (1980, p. 154). En verdad, "El Espíritu habita en la Iglesia y en el corazón de los creyentes como en un templo (1Cor 3,16; 6,19)" (LG, n. 4). Además, el Paráclito conduce al Pueblo de Dios en la verdad, renueva la Iglesia por la fuerza del Evangelio, promueve la unidad en la diversidad, guía la misión, corrobora en los creyentes la obra de Jesús, derrama el amor divino en los corazones, infunde coraje y fortalece el testimonio; Él anima al Pueblo de Dion con sus dones, frutos y carismas (LG, n. 4) $)^{4}$ Y como Dios es Trino, el "ser pneumático" de la Iglesia no es acto aislado de la Tercera Persona, sino que se opera de modo "cristocéntrico y trinitario" (WILLIAMS, 1990, p. 330). Pues, como enseña el Concilio Vaticano II, el Cuerpo de Cristo y el Templo del Espíritu no son dos realidades separadas, sino dos realizaciones de la misma Iglesia, que es una "realidad compleja" (LG, n. 8).

\footnotetext{
${ }^{3}$ Con el 1; At 2.

${ }^{4}$ Con el respectivo fundamento bíblico: 1Jn 16,7-14; Jn 17,20-23; At 2,1-4; Rm 5,5; Rm 8,12-17; 1Cor 12,12-14; Gl 5,22-25; Ap 22,17.
} 
En esta perspectiva, el Concilio Vaticano II reconoce que "el Espíritu vivifica a la Iglesia en la comunión y en el ministerio; y la dota de dones jerárquicos y carismáticos" (LG, n. 4). Eso significa que también los ministerios jerárquicos son dones de participación en la dynamis del Espíritu, para el bien de la comunidad de los creyentes. Lo que opera el Espíritu en Jesús, opera análogamente en la Iglesia, constituyéndola, a la vez, Cuerpo místico y Su propia Morada (LG, n. 4 y 7).

Así nos queda claro que la fe trinitaria y la eclesiología integral correspóndanse; y eso nos ayuda a sanar eventuales reducciones eclesiológicas que separen a lo carismático, de un lado, y a lo institucional, de otro; o que opongan una Iglesia de la Palabra a una Iglesia del Espíritu. Como dice Moltmann,

estas dos perspectivas deben completarse pues donde está la Palabra, ahí está también el Espíritu; en contrario, ya no es Palabra de Dios; y donde está el Espíritu se lo reconoce porque se manifiesta desde la Palabra e ilumina la inteligencia de la fe; en contrario, ya no es Espíritu de Dios (2010, p. 218).

Sin embargo, es comprensible que - después de cierto olvido del Espíritu y la disminución de los carismas en muchas comunidades - la voz pentecostal proclame este antiguo postulado de la teología patrística: "Allí donde está la Iglesia, allí también está el Espíritu de Dios; y allí donde está el Espíritu de Dios, allí está la Iglesia y toda la gracia" (Adv. Haer., III, 24,1).

\subsection{Los carismas, gracias del Espíritu para toda la Iglesia}

Otro elemento importante afirmado en el Diálogo Católico-Pentecostal es la consideración de la entera comunidad de fe: católicos y pentecostales hablan de la "naturaleza carismática de toda la Iglesia" para superar posturas disyuntivas y evitar actitudes clasistas, como si aquellos cristianos dotados de carismas (particularmente las lenguas, profecías y dones milagrosos) formasen algún tipo de élite, por encima de los demás miembros del Cuerpo de Cristo. Al contrario, como mencionamos, el Documento VI sigue la eclesiología de comunión de matriz trinitaria, que concibe la Iglesia simultáneamente como Cuerpo de Cristo y Templo del Espíritu, fundada en la Pascua y en Pentecostés. El ejercicio de carismas por parte de algunos no es atestiguado de privilegio, sino gracia para servir - como también nos dice Lumen Gentium:

[El Espíritu] distribuye a cada uno de los fieles sus dones, según quiere (1Co 12,11 con los que les da aptos y listos para ejercer las diversas obras y deberes que sean útiles para la renovación y la mayor edificación de la Iglesia, según aquellas palabras: «A cada uno se le otorga la manifestación del Espíritu para común utilidad» (1Co 12,7) (LG, n. 12). 
En Pablo los carismas son gracias para servir, presentes en el Cuerpo-Iglesia de modo orgánico y conectivo (1Cor 12,4-7; Ef 4,3-4). Los carismas dinamizan y tensionan la comunidad, pero no determinan una oposición entre dones y ministerios, porque charisma y diakonia provienen del uno Espíritu (HASENHÜTTL, 1973, p. 167-170). En efecto, el mismo Pablo articula dones y ministerios al tratar de los carismas en Romanos 12,6-8 y 1Corintios 12,4-7, así como Pedro enseña: "Que cada cual ponga al servicio de los demás el carisma que ha recibido, como buenos administradores de la multiforme gracia de Dios" (1Pd 4,10).

Antes de proponer una lista cerrada de los dones, o separar dones y ministerios en la praxis eclesial, Pedro y Pablo presentan los criterios para que ambos, dones y ministerios, se ejerciten en reciprocidad y convergencia: primeramente, el "servir" (diakonountes) a que se destina la "gracia recibida" (charisma) como dicho en $1 \mathrm{Pd} 4,10$. Al servir súmanse los tres criterios "que permiten juzgar la validez o la no-validez de los dones del Espíritu: la confesión del Kyrios Iesous [Jesús como Señor] y, desde ahí, la oikodomè - la edificación, y la symphéron - la utilidad para la comunidad" (SCHWEIZER, 1971, p. 180-181: sobre Rm 12 y 1Cor 12). Entonces queda coherente, como dice Pablo, que el servicio, la beneficencia, la enseñanza, la presidencia y las obras de misericordia son carismas, al lado de profecía, sanación, milagros y lenguas (Rm 12,6-8 y 1Cor 12,27-30).

Aunque ni LG n. 12, ni el Documento VI lo mencionen, es justo recordar a Hilario de Poitiers, que define los carismas - específicamente los dones de sabiduría, inteligencia, enseñanza, milagros, curas, hablar en lenguas e interpretarlas - como "servicios y obrares [ministeria et operationes] de la Iglesia Cuerpo de Cristo", no debidos al ingenio humano, pero "procedentes del único Señor Jesucristo, que es el Cuerpo de todos"; de manera que, mediante los carismas, "el don del Espíritu no se queda escondido" (De Trinitate VIII, n. 32-33: POITIERS, 1979, p. 344-345).

Los carismas son expresión "del amor de Dios por su Pueblo y manifestación de su viva Presencia en medio de éste" (Documento VI, n. 9). Además, "libre y soberanamente concedidos por el Espíritu Santo, los carismas capacitan a los creyentes para participar del plan divino de la salvación, para la alabanza y la gloria del Padre" (Documento VI, n. 9). Aunque los católicos relacionen los carismas a los sacramentos de iniciación a la vida cristiana (especialmente el Bautismo y la Confirmación, que es el sacramento de Pentecostés) - mientras que los pentecostales destacan el derramamiento del Espíritu Santo al modo de una inédita unción y efusión de dones - unos y otros respetan la soberana iniciativa del Espíritu Santo, admitiendo que "los carismas no están confinados a los sacramentos, ni al bautismo en el Espíritu Santo" (Documento VI, n. 10). Por el contrario, los carismas deberían favorecer - con los sacra- 
mentos y las virtudes teologales - una vivencia integral de la fe, en el discipulado permanente.

\subsection{Vitalidad de los carismas y primado de la caridad}

El reciente Diálogo Católico-Pentecostal desarrolla una sintética teología de los carismas, y muestra sus implicaciones para las Comunidades católicas y pentecostales:

Los carismas manifiestan la creatividad del Espíritu; son dones generosamente dados y muchas veces superan toda expectativa. Tanto los carismas más extraordinarios (tales como curas, milagros, profecías y lenguas), como aquellos considerados más ordinarios (tales como servicio, enseñanza, exhortación, distribución de donaciones, presidencia y obras de misericordia) son vitales para el ser y la misión de la iglesia (Documento VI, n. 11).

De la parte católica, observamos que esta afirmación es coherente con el magisterio del Concilio Vaticano II:

Además, el mismo Espíritu Santo no sólo santifica y dirige el Pueblo de Dios mediante los sacramentos y los misterios y le adorna con virtudes, sino que también distribuye gracias especiales entre los fieles de cualquier condición, distribuyendo a cada uno según quiere (1Co 12,11) sus dones, con los que les hace aptos y prontos para ejercer las diversas obras y deberes que sean útiles para la renovación y la mayor edificación de la Iglesia, según aquellas palabras: "A cada uno... se le otorga la manifestación del Espíritu para común utilidad" (1Co 12,7) (LG, n. 12).

Dice también:

Estos carismas, tanto los extraordinarios como los más comunes y difundidos, deben ser recibidos con gratitud y consuelo, porque son muy adecuados y útiles a las necesidades de la Iglesia. Los dones extraordinarios no deben pedirse temerariamente ni hay que esperar de ellos con presunción los frutos del trabajo apostólico. Y, además, el juicio de su autenticidad y de su ejercicio razonable pertenece a quienes tienen la autoridad en la Iglesia, a los cuales compete ante todo no sofocar el Espíritu, sino probarlo todo y retener lo que es bueno (1Tes 5,12 y 19-21) (LG, n. 12)

En efecto, el Concilio Vaticano II nos presenta, de lado a lado, los dones más simples (como los siete dones del Espíritu Santo, dichos dones santificantes) y los dones especiales (como los demás dones del Espíritu, dichos dones carismáticos). Sin embargo, tanto el magisterio católico como el Documento VI del Diálogo Católico-Pentecostal evitan hacer una lista o clasificación rígida de los dones, para no restringir la acción del Espíritu a un número cerrado de ejemplos. Antes, católicos y pentecostales consideran importante presentar los criterios bíblicos para discernir los carismas: que sean obra del Paráclito, que concurran a la edificación de la Iglesia, que sirvan al bien de todos, bajo la primacía del amor, en generosa reciproci- 
dad y complementariedad, en el Cuerpo de Cristo (Documento VI, n. 10, 14, 19, a la luz de Rm 12 y 1Cor 12-14). En fidelidad a estos criterios, el ejercicio de los carismas es confiado al discernimiento de la Iglesia, cuya medida será siempre la verdad y la caridad:

Con la asistencia del Espíritu Santo, toda la comunidad de fe - ministros ordenados y fieles laicos - está llamada a comprometerse en un proceso de discernimiento para verificar si ciertas palabras y hechos son manifestaciones genuinas del mismo Espíritu. La Escritura enseña que el criterio último para el discernimiento de los carismas es la verdad y la caridad (1Jn 4,1-3, 1Cor 13,13), siendo que el punto de llegada del nuestro caminar con Dios en Cristo, ya comenzó con el Bautismo y la conversión (Documento VI, n. 12).

Además de afirmar el primado de la caridad en el ejercicio y discernimiento de los carismas, católicos y pentecostales hacen una alerta sobre tendencias que arriesgan desviar el Pueblo de Dios del Evangelio, con pretensiones desmedidas y actitudes vanidosas:

Los carismas son dones del Señor Jesús, resucitado y glorificado en los cielos, mediante su Santo Espíritu (Ef 4,8-12). Dones coherentes con la presencia salvadora de Cristo en el mundo, que no se manifiesta sólo por sus obras de poder, sino también en la debilidad, pobreza y sufrimiento que forman parte de la condición humana (2Cor 12,9). Incluso el más poderoso de los carismas no exime a los cristianos de llevar la cruz y abrazar las exigencias del discipulado. Pentecostales y católicos desafían proféticamente las culturas y las teologías que niegan el valor y el sentido espiritual del sufrimiento. Mientras creen, por ejemplo, que el poder de Dios se manifiesta en las curaciones, milagros y en el bien que Él provee para su Pueblo, son igualmente críticos de todo énfasis que podría llevar a la Iglesia a tendencias escapistas y triunfalistas (Documento VI, n. 13).

La sentencia es precisa y expresa el sentido de responsabilidad de los participantes de este Diálogo: “Incluso el más poderoso de los carismas no exime a los cristianos de llevar la cruz y abrazar las exigencias del discipulado" (n. 13). Así, el Diálogo Católico-Pentecostal nos ofrece aquí y en los siguientes temas del citado Documento VI - una serie de cuidados para el correcto ejercicio de los carismas, ordenados al bien de todos y al testimonio del Señor Crucificado y Resucitado (Documento VI, n. 50-51 y 78-19).

\section{Manifestación de los carismas}

Las manifestaciones carismáticas son plurales, como lo son los carismas. Aunque no tengan cesado, tuvieron un declive en sus expresiones colectivas, hasta el despertar del moderno Movimiento carismático-pentecostal. Las iglesias en este Diálogo reconocen a este Movimiento como un signo 
a ser examinado, pero sin olvidar la presencia de los carismas en la vida mística, cotidiana y misionera de tantos hombres y mujeres, a lo largo de la Historia cristiana.

\subsection{Los carismas en la vida mística y en el testimonio cotidiano}

En este Diálogo, los pentecostales reconocen las dichas gracias místicas (iluminación interior, visiones, operación de curas, palabra de ciencia, palabra profética, discernimiento de los espíritus) verificadas en la Iglesia Católica a lo largo de los siglos, como manifestaciones carismáticas. No solamente gracias miraculosas, sino también carismas del cotidiano: predicación, obras de misericordia, celibato y vida consagrada, promoción de la justicia social, interpretación de los signos de los tiempos y testimonio de fe en la persecución, hasta el martirio - como dice el Documento VI n. $21,30,40,44,51,66$ y 89.

Sobre esto están de acuerdo teólogos católicos como Grasso y Kasper, destacando que "en épocas de particulares dificultades, el Señor no dejó de suscitar personas dotadas de carismas los más variados, para ayudar la Iglesia a vencer las situaciones difíciles y retomar con ardor renovado su lugar en la Historia" (GRASSO, 1982, p. 190). Por otro lado, "cuando se habla de carismas no se debe presumir unilateralmente dones extraordinarios y espectaculares"; pues "los carismas son contextuales y corresponden a la respectiva situación histórica y a las respectivas necesidades de la Iglesia" (KASPER, 2012, p. 189). Ambos autores citan "figuras carismáticas" como Hildegarda de Bingen, Bernardo de Claraval, Francisco de Asís, Brígida, Catalina de Siena, Vicente Ferrer, Teresa de Ávila, Juan de la Cruz, Ignacio de Loyola, Gemma Galgani y Juan XXIII, entre otros (GRASSO, 1982, p. 183-191; KASPER, 2012, p. 189).

También el magisterio católico ha señalado los carismas del Pueblo de Dios. El Papa Juan Pablo II propuso una evangelización nueva en el ardor, en el método y en las expresiones, "arraigada en la fuerza y en la potencia inmorredoras de Pentecostés" (JUAN PABLO II, 1992, Discurso de Apertura). Más recientemente, el Papa Francisco volvió al tema, incluyendo los carismas en el horizonte de la misión, como factores de renovación y comunión para toda la Iglesia y no sólo para los grupos carismáticos o de avivamiento:

El Espíritu Santo también enriquece a toda la Iglesia evangelizadora con distintos carismas. Son dones para renovar y edificar la Iglesia. No son un patrimonio cerrado, entregado a un grupo para que lo custodie; más bien son regalos del Espíritu integrados en el cuerpo eclesial, atraídos hacia el centro que es Cristo, desde donde se encauzan en un impulso evangelizador. Un signo claro de la autenticidad de un carisma es su eclesialidad, su capacidad para integrarse armónicamente en la vida del santo Pueblo fiel de Dios para el bien de todos. Una verdadera novedad suscitada por el Espíritu no necesita arrojar sombras 
sobre otras espiritualidades y dones para afirmarse a sí misma. En la medida en que un carisma dirija mejor su mirada al corazón del Evangelio, más eclesial será su ejercicio. En la comunión, aunque duela, es donde un carisma se vuelve auténtica y misteriosamente fecundo. Si vive este desafío, la Iglesia puede ser un modelo para la paz en el mundo (EG, n. 130).

La reflexión desarrollada es una afirmación de la continua presencia de los carismas en la vida eclesial, con sus diferentes momentos y niveles de expresión. Además de su significado espiritual, los carismas tocan al testimonio y a la misión. El declive de manifestaciones colectivas es un hecho, pero no determina el cese de los dones, como presentamos a seguir.

\subsection{Declinación y renovación de las manifestaciones carismáticas}

Otro aspecto histórico-teológico relacionado a los carismas, es el examen de las causas de su declinación en tiempos posteriores a la era patrística. De hecho, aunque siguieron operando por gracia del Espíritu Santo en la vida interior y en el testimonio de ciertos fieles, se habían vuelto raros en lo colectivo de las comunidades cristianas, hasta el despertar carismático del siglo XX. Sobre eso, el Documento VI admite el declive de las manifestaciones colectivas de los carismas; algo muy distinto de la opinión de que habían perdido su función en la edificación del Cuerpo de Cristo y, por consiguiente, cesado para siempre. En líneas breves, el documento evalúa:

Entre los motivos indicados por los estudiosos para el declive de las manifestaciones carismáticas, están: el amplio ingreso de convertidos - carentes de sólida formación en la fe - luego de la legalización del Cristianismo por el Imperio Romano; la reacción de la Iglesia a los excesos de movimientos carismáticos tales como el Montanismo y el Maniqueísmo, con su desprecio por el cuerpo; una pneumatología aún incipiente, y los esfuerzos teológicos en combatir las varias herejías. Posteriormente, en la Historia, los debates en torno a la Reforma, el Racionalismo iluminista y el escepticismo generalizado por todo lo que fuera sobrenatural también contribuyeron a la escasa expectativa de las manifestaciones extraordinarias del Espíritu Santo (Documento VI, n. 22).

Em seguida, el Documento hace referencia al moderno Movimiento pentecostal-carismático como un signo, entre otros, de continuidad y vitalidad de los carismas en la Iglesia:

Católicos y pentecostales están de acuerdo en admitir que el avivamiento Pentecostal del siglo XX acarreó una nueva atención a los carismas como algo esencial para revigorizar la vida y la misión de la Iglesia. Esta misma atención a los carismas alcanzó mayor intensidad con el surgimiento de la Renovación en el Espíritu Santo en las Iglesias Anglicana y Protestantes en los años cincuenta y sesenta, y con el surgimiento de la Renovación Carismática Católica en 1967. También se reconoce el papel particular que la enseñanza del Concilio 
Vaticano II tuvo para la revitalización de los carismas en general, además de afirmar la importancia de la dimensión carismática de la Iglesia (LG, n. 12) (Documento VI, n. 23).

Importa, sin embargo, adelantar que esta apreciación es lectura de una señal reciente; nunca afirmación de cualquier supuesta exclusividad de los carismas de la parte de Comunidades avivadas o renovadas. Porque el Espíritu sopla donde quiere, distribuyendo sus dones al entero Cuerpo de Cristo, para el bien de todos (1Cor 12,7):

Juntos, católicos y pentecostales reconocen que los carismas concedidos por el Espíritu Santo al Pueblo de Dios pretenden ser recibidos por todos los cristianos: no se limitan sólo a los que participan en movimientos de «avivamiento» o «renovación». Orar para recibir los carismas, esperar por su manifestación y velar por su ejercicio responsable resulta en la edificación de la Iglesia y en la eficacia de su ministerio en el mundo. En consecuencia, católicos y pentecostales se sienten invitados a redescubrir el papel de los carismas y a reavivar el uso de esos dones en sus respectivas comunidades. Los participantes de este Diálogo animan a los demás cristianos a hacer lo mismo (Documento VI, n. 105).

Queda claro que la experiencia de los carismas no es, ni debe ser, exclusividad de los avivados y carismáticos. Por otra parte, el Documento espera que las comunidades en general - así como otras iglesias (protestantes, reformadas, ortodoxas...) - sean más receptivas a los carismas, como impulso a los ministerios.

\section{La Iglesia en permanente Pentecostés}

Católicos y pentecostales profesan a la Iglesia como comunidad mesiánica y templo del Espíritu (1Pd 2,4-5). Como hemos dicho anteriormente, el Espíritu Santo no sólo representa una dimensión de la Iglesia, sino que es constituyente de la Iglesia con Cristo; Él habita el Pueblo de Dios y lo unge como pueblo escatológico, profético y sacerdotal. Así, el Pentecostés no queda en el pasado, como memoria de un hecho lejano, sino que es un evento que funda y mantiene a la Iglesia a través de la historia, conformándola a Cristo y confirmándola en la misión:

Juntos, pentecostales y católicos afirman que, desde Pentecostés, el Espíritu Santo ha constituido y animado a la Iglesia - la nueva comunidad escatológica de Dios - llevándola a proclamar y manifestar continuamente su Reino. A partir de Pentecostés, el Espíritu capacitó vigorosamente a los discípulos para llevar adelante la misión de su Señor, mientras Dios corroboraba el testimonio del Evangelio con señales y prodigios hechos en el nombre de Jesús y por el poder del mismo Espíritu (Mc 16,17-18; Hch 2,4; Hb 2,4). La Iglesia es, pues, misionera por su propia naturaleza. Y el Espíritu Santo es el primer agente de la misión eclesial; es quien dirige y capacita a la Iglesia en toda su actividad (Documento VI, n. 24). 
Reconocer al Espíritu como constituyente de la Iglesia de Cristo implica en disponerse a un renovado Pentecostés. La referencia al Reino y a la misión señalan los amplios horizontes de la acción del Paráclito, objetivando su manifestación más allá de la experiencia subjetiva: los carismas corroboran la Palabra anunciada y dinamizan el ministerio de los evangelizadores.

\subsection{Integración entre Eclesiología y Pneumatología}

Tenemos aquí una de las contribuciones de la tradición pentecostal, que es acercar - de modo más simple y directo - la Pneumatología y la Eclesiología:

Dios señala a los creyentes con el sello del Espíritu Santo (2Cor 1,21-22), el cual habita en cada uno como en un templo (1Cor 6,19). Por medio del mismo Espíritu, los creyentes son santificados y hechos «piedras vivas en la construcción de la casa habitada por el Espíritu, para constituir una santa comunidad sacerdotal, para ofrecer sacrificios espirituales agradables a Dios por Jesucristo» (1Ped 2,5) (Documento VI, n. 25).

El Espíritu Santo constituye efectivamente la Iglesia con sus dones, en consonancia con la voluntad del Padre y la obra consumada por el Hijo (LG, n. 2-4). De esta eclesiología trinitaria brota la adecuada articulación entre la obra del Cristo (Pascua) y la obra del Espíritu (Pentecostés) en la fundación del nuevo Pueblo de Dios. En efecto, la Trinidad es arché de la Iglesia, como lo demuestran varios pasajes del Nuevo Testamento ${ }^{5}$ (Mt 28,19; Jn 15,26; Hch 2,33; 1Cor 12,4-6; Ef 1,17).

A la luz de Pentecostés, el Documento VI reconoce los carismas como componentes de la Iglesia, como elementos propios de su fundación y perpetuidad por parte del Espíritu de Cristo, cuidando en no reducirlos a aquellos dichos extraordinarios o milagrosos, pues también la presidencia, la enseñanza, la beneficencia y las obras de misericordia son carismas, según Pablo en Romanos 12,6-8. Esto no se refiere sólo al primer Pentecostés, como si fuera un hecho pasado, sino a la acción continua del Paráclito, a suscitar un nuevo Pentecostés en el presente y en el futuro de la Iglesia:

El Espíritu dota a los creyentes con dones espirituales para la edificación del Cuerpo de Cristo. El mismo Espíritu es también el principio de la unidad (koinonia) en medio de la diversidad de carismas y ministerios (1Cor 12,4-5). Tanto Dios distribuye los carismas libre y soberanamente, como invita a sus hijos a beber en la fuente del Donante de los dones, para confirmar las gracias ya recibidas y seguir deseando, confiadamente, sus dones (Documento VI, n. 26).

No se propone un modelo unilateral para la experiencia de los dones, sino que se admiten expresiones carismáticas nuevas y distintas en el tiempo presente de las iglesias, con sus énfasis teológicos y litúrgicos igualmente

${ }^{5}$ Véanse Mt 28,19; Jn 15,26; Hch 2,33; 1Cor 12,4-6; Ef 1,17. 
distintos. La comunión se hace con diversidad de gracias y dones, en la unidad del Donante: "Hay diversidad de carismas, pero un mismo Espíritu" (1Cor 12,4). A esta altura del Documento, los pentecostales destacan positivamente las proposiciones del Concilio Vaticano II sobre los carismas en la misión de los fieles laicos (los creyentes bautizados, pero no ordenados):

Pentecostales se sienten alentados por la enseñanza de la Iglesia Católica, de que "de la aceptación de estos carismas, incluso los más simples, brota en favor de cada uno de los fieles el derecho y el deber de ejercerlos para el bien de la humanidad y la edificación de la Iglesia, dentro de la misma Iglesia y del mundo, en la libertad del Espíritu Santo que sopla donde quiere (Jn 3,8)" (AA, n. 3, también LG, n. 12; Documento VI, n. 26).

Esta mención de AA n. 3 y LG n. 12 señala la misión de los fieles laicos, animados por carismas específicos, muy variados en la realidad de las iglesias. Servir al bien de la humanidad y edificar a la iglesia en el mundo son criterios para valorar las expresiones carismáticas, coherentes con la universalidad de Pentecostés ${ }^{6}$.

\subsection{Dimensión institucional y carismática, coesenciales a la Iglesia}

Los dones del Espíritu, sin embargo, no se reducen a las expresiones de alabanza, sanación, lenguas y profecías. Como hemos señalado antes, también los ministerios ordenados, la presidencia, la enseñanza y los servicios de supervisión de la Iglesia participan en la Unción del Paráclito, expresando la íntima articulación de las dimensiones institucional y carismática:

Católicos y pentecostales están de acuerdo de que el Espíritu Santo dota a la Iglesia con dones institucionales y carismáticos (1Cor 12,28). En la dimensión institucional de la Iglesia, el Espíritu Santo está operando a través de las estructuras de liderazgo establecidas por Cristo. En la dimensión carismática, el mismo Espíritu opera entre los creyentes de todos los niveles, de modo continuo, libre y muchas veces imprevisible. Estas dos dimensiones son coherentes a la Iglesia y complementarias entre sí. La dimensión institucional tiene, por así decir, un rasgo carismático, en todo cuanto en ella es animado y continuamente sostenido por el Espíritu Santo; y la dimensión carismática tiene, por su parte, un rasgo institucional, en todo lo que en ella debe ser discernido por la Iglesia y correctamente ordenado para el bien de toda la Iglesia. Católicos y pentecostales reconocen y aprecian la existencia de una saludable tensión entre las dimensiones carismática e institucional, en la Iglesia. A ambas se aplica esta amonestación de Pablo: "En nombre de la gracia que me ha sido dada, digo a cada uno de vosotros: no tengáis pretensiones más allá de lo razonable; sino una justa estima de sí mismos, dictada por la sabiduría, de acuerdo con la medida de la fe que Dios concedió a cada uno" (Rm 12,3) (Documento VI, n. 27).

\footnotetext{
${ }^{6}$ Como se presenta en At 1,$8 ; 2,17 ; 10,45$ y 11,15-16.
} 
De este modo, los pentecostales muestran su acuerdo con lo que dice el Concilio Vaticano II: "El Espíritu Santo unifica a la Iglesia en la comunión y en el ministerio; la dota y la dirige mediante los diversos dones jerárquicos y carismáticos" (LG, n. 4). En la vivencia de las Comunidades hay, ciertamente, una tensión entre los dones jerárquicos (o ministeriales) y los dones carismáticos (o espirituales), convocando a los creyentes a la humildad, discernimiento y corresponsabilidad en la edificación de la Iglesia. Esta tensión se considera positiva en la medida en que expresa la interacción y la complementariedad entre las dimensiones carismática e institucional de la Comunidad de fe. En efecto, ambas "son coesenciales" a la Iglesia (JE, n. 13).

\subsection{Servicio y discernimiento}

Sobre la relación entre dones carismáticos y dones jerárquicos, mencionada anteriormente, el Documento dice lo esencial. Toca a las Iglesias proseguir el tema en sus propias instancias. Sin embargo, hay una indicación importante: la afirmación de que todo don institucional (o jerárquico) constituye en la Iglesia un servicio, un instrumento ministerial en favor del bien y de la misión de todos, a ejemplo de Cristo que "no vino para ser servido, sino para servir y dar la vida en rescate por muchos" (Mc 10,45):

Pentecostales y católicos tienen una común comprensión de que el Espíritu Santo suscita líderes y los califica con dones, para que enseñen y conduzcan a la comunidad cristiana, ayudándola a crecer en santidad. La autoridad en la Iglesia es un don de Dios y debe ser ejercida como verdadero servicio, siguiendo el ejemplo del Señor Jesús (Mc 10,42-45). Porque Cristo mismo es el supremo pastor de la Iglesia (1Pdr 5,4). Católicos entienden el liderazgo en la Iglesia, primero, conforme al triple ministerio de obispos, presbíteros y diáconos. Los pentecostales aclaran que, en las Comunidades pentecostales clásicas, hay una estructura de liderazgo semejante, con ministerios instituidos; sin embargo, el ejercicio de la supervisión eclesial puede tener expresiones más amplias. Ambos reconocen que la autoridad, en la Iglesia, debe ser ejercida conforme a la guía del Espíritu Santo, para evitar los riesgos de usarla inapropiadamente (Documento VI, n. 28).

Por cierto, el servicio de la autoridad y la supervisión pastoral "bajo la guía del Espíritu" es condición irrenunciable para bien articular carisma e institución, cuidando de la comunión eclesial. Sin embargo, las tensiones entre carisma e institución perduran y desafían a las Iglesias a evaluar sus prácticas, para superar los eventuales abusos de poder, el clericalismo, las tendencias individualistas, la idolatría del dinero y otros problemas. La busca de soluciones exige la corresponsabilidad de todos y todas, laicos y pastores, en instancias congregacionales y sinodales donde se ejercita la accountability: prestar cuentas y responsabilizar a cada cual por sus actos (n. 82 y 98). Son contextos en que el servicio viene ayudado por el discernimiento, para distinguir lo verdadero de lo falso y asegurar el bien común de fieles y pastores en la Iglesia. 
En este sentido, Rahner valoriza el discernimiento "inspirado por Dios" que pueda iluminar una determinada situación "en carácter profético" (1961, p. 34), por ejemplo, delante de desafíos sin precedentes al dogma y al magisterio eclesiástico (1961, p. 34). Claro, aquí reverbera la noción jesuítica del discernimiento como carisma, según la escuela ignaciana: discernir la voluntad de Dios en el tiempo presente y elegir los medios para llevársela a cabo de modo duradero, desde hoy adelante, a la luz de la Palabra, con la intención recta de glorificar a Dios y corresponder a Su gracia salvífica (LOYOLA, 1966, p. 105-109). Discernir es una operación pneumática fundamental, que implica la voluntad y la inteligencia de la persona creyente, en cuanto miembro del Cuerpo de Cristo, en su condición bautismal de sujeto de la gracia - anterior a las distinciones ministeriales, aunque no las excluya.

El discernimiento puede usar mediaciones analíticas y dialécticas, como sostiene Libanio (1977, p. 62-89), pero nunca se cancela su carácter teologal. Comprometido con la fe, la esperanza y la caridad, el sujeto que discierne se pone a la disposición del Paráclito, abierto a "momentos de intuición mística y profética" (1977, p. 103):
Son características de este momento la claridad de espíritu, la certitud interior, la tranquilidad en la elección, mediante la intuición de que tal cosa [o decisi- ón] se le es pedida, incluso si le presentan a la persona motivos en contrario, que no tengan una respuesta racional o lógica. No se deja enredar por ningún sofisticado raciocinio de opositores o interrogadores. La certeza no se ve sacu- dida por las amenazas, por el caos de la solitud o por la originalidad de una decisión inspirada. Y muchas veces son decisiones que suponen ruptura con profundos lazos afectivos. [...] Cuanto más radical y original es la decisión, más claridad de espíritu se requiere (1977, p. 104).

En este sentido, católicos y pentecostales admiten el discernimiento como proceso espiritual, involucrado en un camino de conversión (Documento VI, n. 96-98) que tiene al centro la caridad, con base en 1Cor 13 (Documento VI, n. 12): esta remisión bíblica nos advierte que "la caridad es el mayor carisma y el carisma que mueve a todos los demás" (COMBLIN, 1987, p. 149).

En cuanto a la relación entre servicio y discernimiento en la Iglesia, sirve también el apartado sobre discernimiento de los espíritus en el mismo Documento VI, párrafos n. 73-90. A pesar de los distintos énfasis del discernimiento en el uso eclesial - los pentecostales lo ejercitan como examen de las profecías pronunciadas en sus congregaciones; los católicos, como búsqueda de la voluntad de Dios en su vida y misión - ambos lo admiten como "carisma" que "equipa al Pueblo de Dios para distinguir lo que es verdadero de lo que es falso o erróneo" en términos de "manifestación espiritual" (n. 73). Unas pocas líneas después, el Documento destaca la responsabilidad que el discernimiento conlleva para el ejercicio de los carismas en general: 
La práctica disciplinada del discernimiento ayuda a la comunidad reunida a manifestar con libertad a los demás carismas, en un ambiente de acogida y aliento, en la cual los fieles prestan cuenta y son responsabilizados por sus actos. Esto cumple lo que Pablo dice, en su clara exhortación a la Iglesia de Tesalónica: “No extingáis el Espíritu; no despreciéis las profecías; examinadlo todo y quedaos con lo bueno" (1Tes 5,19). Los creyentes son invitados a vivir en la libertad del Espíritu Santo, ejercitando los carismas con la confianza de que el mismo Espíritu les capacita con el don de discernir los espíritus, protegiéndolos de las falsas doctrinas y preservándolos de las divisiones (Documento VI, n. 77).

Fijémonos que la responsabilización (accountability en el original inglés), se la pide a "los fieles" (the believers en el original inglés); es decir, se la pide a todos los miembros de la Iglesia como creyentes: todos son corresponsables en discernir los carismas - fieles laicos y ministros, cada cual desde su lugar - a la luz de la verdad evangélica (= protegerse de las falsas doctrinas) y en vista de la comunión (= preservarse de las divisiones). Con eso, se quiere prevenir la comunidad de situaciones en las cuales los carismas, ejercidos sin discernimiento, puedan no servir a la edificación y a la evangelización.

\section{Consideraciones finales}

Ante todo, reiteramos la invitación a una lectura integral del Documento VI, a la cual este artículo sirve como punto de partida. Y con respecto a lo que se presentó hasta aquí, tejemos dos consideraciones: cuanto al contenido y a la recepción del documento.

a) Sobre el contenido:

Ciertamente este Diálogo promociona la articulación entre Pneumatología y Eclesiología, con atención al terreno pastoral de las Iglesias participantes. Sin embargo, nos parece importante destacar un aspecto, central para la teología católica: la relación entre Espíritu y Sacramentos en la Iglesia. Similar a la observación de Moltmann sobre la relación entre Espíritu y Palabra, muy candente para la eclesiología reformada y luterana (2010, p. 218), se pone la relación entre Espíritu y Sacramentos para la Iglesia Católica, especialmente los sacramentos de Iniciación Cristiana (Documento VI, n. 9-10).

El bautismo comunica el don del Espíritu e incluye, en el Rito, una unción que "señala la participación del cristiano en el sacerdocio real de Jesucristo" (BARGELLINI, 1979, p. 251); mientras la confirmación - o mejor, la crismación - actualiza en plenitud "la efusión especial del Espíritu Santo tal cual fue otorgado a los Apóstoles en el día de Pentecostés" y "aumenta en 
nosotros los dones del Espíritu Santo" (CIC, n. 1302-1303). De esta manera la crismación "perpetúa en la Iglesia la gracia de Pentecostés", comunicando "la fuerza y la gracia del Espíritu Santo" (CIC, n. 1288 y 1310).

El vínculo entre el bautismo y la crismación no es estático, sino dinámico, pasando del don infundido a los dones efusos (carismas), en una misma economía del Espíritu. Entre los muchos acercamientos sobre como bautismo y crismación se relacionan, Laurentin considera que la mejor perspectiva "en sentido global es aquella que refiere el bautismo y la confirmación, respectivamente, a la Pascua y a Pentecostés" (1974, p. 48). O como dice Codina: "la dualidad bautismo-confirmación reproduce, en nivel sacramental, la dualidad trinitaria entre Cristo y el Espíritu" (2019, p. 95).

Este aspecto obviamente excede a nuestras páginas; pero es importante tenerlo presente en el Diálogo Católico-Pentecostal - como señaló el Documento anterior, de la Quinta Etapa - porque del punto de vista católico necesitamos aclarar cómo se definen y relacionan el sacramento de la crismación y el bautismo en el Espíritu Santo (CIDCaP, 2010, p. 115-144).

b) Sobre la recepción:

¿Cómo llegaron católicos y pentecostales, con tantas diferencias entre ellos, a un Documento tan esclarecedor y propositivo? Los mismos participantes responden:

Los católicos reconocen que los Pentecostales han suscitado una mayor sensibilidad hacia el derramamiento del Espíritu Santo y el ejercicio de sus dones en la Iglesia contemporánea. Los pentecostales, por su parte, no comprenden el derramamiento del Espíritu por ellos experimentado como algo confinado a las Iglesias Pentecostales, pero consideran los carismas como un don para la Iglesia en su totalidad. Además, están agradecidos por el hecho de que los católicos, así como otros cristianos, han reconocido el testimonio pentecostal sobre el valor de los carismas para la vida de la Iglesia. Juntos, católicos y pentecostales admiten el derramamiento del Espíritu Santo como gracia para el entero Cuerpo de Cristo; gracia que trasciende incluso sus propias expectativas (Documento VI, n. 14).

Tal afirmación expresa la fraternidad, confianza y reconocimiento mutuo que se ha consolidado entre católicos y pentecostales a lo largo de este Diálogo; y nos advierte sobre las actitudes de recepción de sus resultados por parte de las Iglesias y sus comunidades locales. De un lado, los participantes declaran "que el propio Diálogo constituye una forma de experiencia carismática, llena de los dones del Espíritu", donde pudieron degustar "las inspiraciones proféticas del Espírito que se manifestaban en cada cual", a lo largo de las "oraciones, debates y encuentro fraternal" (Documento VI, n. 108). De otro lado, la distancia y desconfianza que aún prevalecen en amplios espacios de nuestras Comunidades exigen una real conversión de corazón al propósito de la unidad - "Que sean uno" (Jn 
17,21) - en términos de relación, espiritualidad y formación teológico-pastoral. El obispo metodista Paulo Ayres Mattos reconoce que

[...] la Pneumatología pentecostal refleja de alguna forma la Pneumatología católica, al recolocar la persona y obra del Espíritu Santo en el centro de la vida eclesial. Así siendo, todos los seis Documentos Finales del Diálogo católico-pentecostal plantean cuestiones significativas tanto para el anti-pentecostalismo católico, cuanto para el anti-catolicismo pentecostal, practicados por diferentes segmentos de ambas tradiciones en Latinoamérica" (2018, p. 51).

De hecho, los resultados del Diálogo no encuentran condiciones para una recepción adecuada donde aún duran el proselitismo, el desprecio mutuo, la ausencia de diálogo, el burocratismo eclesiástico, la lucha por poder político y mediático, como analiza el científico de la Religión e investigador pentecostal Gedeon Alencar (2018, p. 70-109). Sin embargo, para cambiar este escenario tienen mucho valor las Redes ecuménicas, como RELEP (Red Latinoamericana de Estudios Pentecostales), las plataformas de encuentro entre católicos y pentecostales (CRECES en Argentina, ENCRISTUS en Brasil, JOHN 17 en Norteamérica, KAIROS en Europa, CLF en nivel mundial), el ministerio de unidad por parte de los movimientos carismáticos y otras señales de respeto, cercanía y colaboración entre pentecostales clásicos y católicos (ALENCAR, 2018, p. 144-154).

Insistir en el encuentro y la disposición no es superfluo, sino que incide en el método del Diálogo Católico-Pentecostal, tradicionalmente atento a las relaciones y no solo a los contenidos, acercando lo teologal y lo teológico:

Los participantes de este Diálogo confían este Informe a los demás, con la esperanza de que sus conclusiones desafíen a los lectores y lectores a la fe más profunda en el Evangelio, en una apertura sin fronteras al Espíritu Santo de Dios, para que crezca el sincero aprecio por todos los discípulos del Señor Jesús Cristo. Los participantes de esta sexta etapa del Diálogo Internacional Católico-Pentecostal están convencidos de que resultados de este porte, pueden servir efectivamente para llevar a los católicos y los pentecostales a estar más cerca unos de otros. A medida que crecen juntos hacia Cristo, haciéndose más cerca de Él, sostenidos por el Espíritu Santo que los guía constantemente, los católicos y pentecostales de este Diálogo esperan y oran para que muchos otros se junten a ellos en la disposición de responder al llamamiento de unidad que el Señor les hace (Ef 4,3). La participación en esta jornada, caminando siempre hacia adelante, constituye una dádiva sustancial a la promoción de la unidad de los cristianos. (Documento VI, n. 114)

En efecto, este Diálogo favoreció la revisión histórica de la experiencia de las Iglesias, ayudó a percibir énfasis complementarios entre pentecostales y

${ }^{7}$ CRECES - Comunión Renovada de Evangélicos y Católicos en el Espíritu Santo, ENCRISTUS - Encontro de Cristãos em Busca de Unidade e Santidade, JOHN 17 - John 17 Movement of Unity, KAIROS - Kairos International Meeting, CLF - Charismatic Leaders Fellowship. 
católicos, resolvió muchos malentendidos, desarrolló nuestra comprensión del lenguaje y la conciencia común de que hay "un solo Señor, una sola fe, un solo Espíritu" (Ef 4,4-5).

\section{Siglas}

$\begin{array}{ll}\text { AA } & =\text { Apostolicam Actuositatem } \\ \text { Adv.Haer } & =\text { Adversus haereses } \\ \text { CIC } & =\text { Catecismo de la Iglesia Católica } \\ \text { CLF } & =\text { Charismatic Leaders Fellowship } \\ \text { CIDCaP } & =\text { CIDCaP } \\ \text { CRECES } & =\text { Comunión Renovada de Evangélicos y Católicos } \\ & \text { en el Espíritu Santo } \\ \text { EG } & =\text { Evangelii Gaudium } \\ \text { ENCRISTUS } & =\text { Encontro de Cristãos em Busca de Unidade e Santidade } \\ \text { Documento VI }= & \text { “No extingáis el Espíritu” (1Tes 5,19) - Los carismas en la } \\ & \text { vida y en la misión de la Iglesia } \\ \text { ICCaPD } & =\text { International Commission for Catholic-Pentecostal Dialogue } \\ \text { JE } & =\text { Juvenescit Ecclesia } \\ \text { JOHN 17 } & \text { John } 17 \text { Movement of Unity } \\ \text { KAIROS } & \text { Kairos International Meeting } \\ \text { LG } & =\text { Lumen Gentium } \\ \text { PCUC } & =\text { Pontifício Conselho para a Unidade dos Cristãos } \\ \text { RELEP } & =\text { Red Latinoamericana de Estudios Pentecostales }\end{array}$

\section{Referencias}

ALENCAR, G. F. de. Ecumenismos \& Pentecostalismos. São Paulo: Recriar, 2018.

AYRES MATTOS, P. Observações sobre o Relatório da Sexta Fase do Diálogo Internacional Católico-Pentecostal (2011-2015). In: LIMA, A. COSTA, M. C.C.; GANDRA, V. R. (Orgs.). O Espírito e as Igrejas. São Paulo: Recriar, 2018. p. 50-54.

BARGELLINI, E. Lo Spirito Santo nei sacramenti dell'iniziazione cristiana. In: Parola, Spirito e Vita. Bologna: EDB, 1979. n. 4, p. 244-255.

CODINA, V. O Espírito do Senhor: força dos fracos. São Paulo: Paulinas, 2019.

COMBLIN, J. El Espíritu Santo y la liberación. Madrid: Paulinas, 1987.

COMISSÃO INTERNACIONAL DE DIÁLOGO CATÓLICO-PENTECOSTAL. Tornar-se cristão: inspiração da Escritura e dos textos da Patrística com algumas reflexões contemporâneas. Brasília: CNBB, 2010. Edición brasileña del Final Report 1998-2006: On becoming a Christian (V Phase). 
COMISSÃO INTERNACIONAL DE DIÁLOGO CATÓLICO-PENTECOSTAL. “Não extingais o Espírito" (1Ts 5,19) - Os carismas na vida e na missão da Igreja. In: LIMA, A.; COMMISSIONE INTERNAZIONALE DEL DIALOGO CATTOLICO-PENTECOSTALE. Rapporto Finale 1972-1976. In: Enchiridion Oecumenicum. Bologna: EDB, 1994. v. 1, p. 1076-1077.

COMMISSIONE INTERNAZIONALE DEL DIALOGO CATTOLICO-PENTECOSTALE. Rapporto Finale 1977-1982. In: Enchiridion Oecumenicum. Bologna: EDB, 1995. v. 3, p. 901-924.

COMMISSIONE INTERNAZIONALE DEL DIALOGO CATTOLICO-PENTECOSTALE. Prospettive sulla koinonia: rapporto finale 1985-1989. In: Enchiridion Oecumenicum. Bologna: EDB, 1995. v. 3, p. 926-957.

CONCILIO VATICANO II. Apostolicam Actuositatem. Disponible en: <http://www.vatican.va/archive/hist_councils/ii_vatican_council/documents/vat-ii_decree_19651118_ apostolicam-actuositatem_sp.html> Acceso: 10 jul. 2020.

CONCILIO VATICANO II. Lumen Gentium. Disponible en: <http://www.vatican.va/ archive/hist_councils/ii_vatican_council/documents/vat-ii_const_19641121_lumen-gentium_sp.html>. Acceso: 10 jul. 2020.

CONGREGACIÓN PARA LA DOCTRINA DE LA FE. Carta Juvenescit Ecclesia: sobre la relación entre dones jerárquicos y carismáticos para la vida y misión de la Iglesia [2016]. Disponible en: <https://press.vatican.va/content/dam/salastampa/ it/fuori-bollettino/pdf/PO\%20 IUVENESCIT\%20ECCLESIA_Portugues.pdf $>$. Acceso: 12 dic. 2019.

COSTA, M. C.C.; GANDRA, V. R. (Orgs.). O Espírito e as Igrejas. São Paulo: Recriar, 2018. p. 226-267. Edición brasileña del Documento VI, en inglés Final Report VI 2011-2015: the Charisms in the Life and in the Mission of the Church (VI Phase).

FRANCISCO, Papa. Exhortación apostólica "Evangelii gaudium" [2013]. Disponible en: $<$ http://www.vatican.va/content/francesco/es/apost_exhortations/documents/papa-francesco_esortazione-ap_20131124_evangelii-gaudium.html>. Acceso: 10 dic. 2019.

GRASSO, D. I carismi nella chiesa. Brescia: Queriniana, 1982.

HASENHÜTTL, G. Carisma, principio fondamentale per l'ordinamento della Chiesa. Bologna: EDB, 1973.

INTERNATIONAL COMMISSION FOR CATHOLIC-PENTECOSTAL DIALOGUE. Do not quench the Spirit: Charisms in the life and mission of the Church. In Information Service [2016]. Disponible en: <http://www.vatican.va/roman_curia/pontifical_councils/chrstuni/information_service/pdf/information_service_147_en.pdf $>$. Acceso: 08 dic. 2019.

LION, I. de. Contra as heresias [Adversus haereses]. 3.ed. São Paulo: Paulus, 2009. LOYOLA, Inácio de. Exercícios espirituais. Porto Alegre: Edição da Província Brasil Meridional da Companhia de Jesus, 1966.

JUAN PABLO II, Papa. Discurso de apertura de la IV Conferencia General del Episcopado Latino-Americano apud Documento de Santo Domingo [1992]: Disponible en: <http://w2.vatican.va/content/john-paul-ii/pt/speeches/1992/october/documents/ hf_jp-ii_spe_19921012_iv-conferencia-latinoamerica.html>. Acceso: 03 dic. 2019. 
JUAN PABLO II, Papa (prom.). Catecismo de la Iglesia Católica [1997]. Disponible en: $<$ http://www.vatican.va/archive/catechism_sp/index_sp.html>. Acceso: 08 dic. 2019.

LIBANIO, J. B. Discernimento e política. Petrópolis: Vozes/CRB, 1977.

LAURENTIN, R. Pentecôtisme chez les catholiques. Paris: Beauchesne, 1974.

MOLTMANN, J. O Espírito da Vida. 2.ed. Petrópolis: Vozes, 2010.

MÜHLEN, H. Fé cristã renovada: carisma, Espírito, libertação. São Paulo: Loyola, 1980.

POITIERS, H. de. De Trinitate. In: SMULDERS, P. (Ed.). Corpus Christianorum Series Latina. Turnhout: Brepols, 1979. v. 62.

PONTIFÍCIO CONSELHO PARA A UNIDADE DOS CRISTÃOS. Diálogo católico-pentecostal. $2^{\mathrm{a}}$ ed. São Paulo: Paulinas, 1999. Edición brasileña del Final Report 1990-1997: Evangelisation, Proselytism and Common Witness (IV Phase).

RAHNER, K. Visioni e profezie. Brescia: Morcelliana, 1961.

SCHWEIZER, E. Le Nouveau Testament. In: KITTEL, G (Éd.). Ésprit - Dictionnaire biblique. Genève: Labor et Fides, 1971. p. 127-233.

WILLIAMS, J. R. Renewal Theology. Grand Rapids: Zondervan Publishing House, 1990. v. 2.

Artículo sometido en 16.03.2020 y aprovado en 12.08.2020.

Marcial Maçaneiro Doctor en Teología por la Pontificia Universidad Gregoriana (Roma), profesor del Programa de Posgrado en Teología de la Pontificia Universidad Católica del Paraná PUCPR (Curitiba). Experto de la Comisión Internacional de Diálogo Católico-Pentecostal (Vaticano). Presbítero de la Congregación de los Sacerdotes del Corazón de Jesús (Dehonianos). Posdoctorado en Teología en curso, en la Universidad Católica Portuguesa UCP (Lisboa). Orcid.org/0000-0003-3085-8588. E-mail: marcialscj@gmail.com

Dirección: Rua Guabirotuba 158

Bairro Prado Velho

80.215-200 Curitiba - PR 